\title{
NAS PÁGINAS DO MULHERIO (1981-1988): UM PANORAMA SOBRE A CRÍTICA LITERÁRIA FEMINISTA E A QUESTÃO HISTORIOGRÁFICA
}

\author{
Jaísa Girardi Morais \\ Virgínea Novack Santos da Rocha
}

Resumo: Partindo-se da análise das 41 edições do jornal Mulherio, posterior Nexo - Feminismo, informação e cultura, que circulou entre 1981 e 1989, buscou-se perceber o modo como o periódico feminista aborda questões sobre literatura produzidas por mulheres e a suas participações na historiografia literária, levando-se em consideração os diversos processos de inferiorização, silenciamento, exclusão e a apagamentos que escritoras mulheres e suas literaturas são submetidas pela crítica hegemônica. Nesse sentido, foi possível perceber que há no jornal um grande interesse na recuperação de escritoras do passado e divulgação de escritoras do presente da publicação, além do interesse em discutir temas próprios à "escrita feminina", isto é, uma crítica literária própria à literatura de mulheres. Dessa forma, a partir desses dois movimentos do próprio Mulherio foi possível recuperar e analisar situações contextuais de sua exclusão escritoras relativamente grande circulação ao seu tempo, mas ainda assim excluídas do cânone oficial das histórias literárias: Cassandra Rios, Maria Elisabete Lima Mota e Dinorath do Valle.

Palavras-chave: Mulherio. Crítica literária feminista. Historiografia.

Abstract: Based on the analysis of the 41 editions of the journal Mulherio, later Nexo - Feminism, information and culture, which was published in between 1981 and 1989, we sought to understand how the feminist journal addresses issues about literature produced by women and their participation in historiography literary, taking into account the various processes of inferiorization, silencing, exclusion and the erasures that female writers and their literatures suffer from hegemonic criticism. In this sense, it was possible to perceive that there is a great interest to the newspaper in the recovery of writers from the past and dissemination of writers from the present of the publication. In addition, they were also interested in themes like "female writing", a literary criticism specific to the literature of women. Thus, from these two main 
concerns by the Mulherio it was possible to recover and analyze the context of their exclusion, writers relatively important at the time, but still excluded from the official canon of literary history: Cassandra Rios, Maria Elisabete Lima Mota and Dinorath do Valle.

Keywords: Mulherio. Feminist literary criticism. Historiography

\section{CONSIDERAÇÕES INICIAIS}

Para que o Estado democrático de direito seja garantido, uma das suas mais importantes manifestações é a liberdade de imprensa. Por esse motivo, em períodos de autoritarismo, a imprensa é um dos primeiros setores a ter a sua liberdade cerceada. Esse foi o caso, por exemplo, em 1937, quando Getúlio Vargas cria o Departamento de Imprensa e Propaganda (DIP) ou em 1968 na situação da promulgação do Ato Institucional $n$ o 5, que suspendia a Constituição de 1964 bem como os direitos individuais e políticos e criava um código penal militar que permitia ao exército brasileiro e à polícia militar agir sem qualquer revisão judicial, institucionalizando a censura aos indivíduos e aos meios de comunicação.

No entanto, embora a imagem da censura institucional pareça ser a única grande forma de silenciamento, não é possível perceber, até mesmo em momentos de democracia, uma pluralidade de vozes a partir dos grandes meios 
de comunicação em massa ${ }^{1}$, uma vez que uma série de estruturas de poder autorizam a circulação de determinadas vozes, como é o caso de mulheres, LGBTQIs, pessoas negras, indígenas e outros tantos grupos identitários historicamente silenciados. Esse procedimento discursivo pode ser traduzido nas palavras de Michel Foucault (2011) ao afirmar que "em toda a sociedade a produção do discurso é ao mesmo tempo controlada, organizada e redistribuída por certo número de procedimentos que têm como função [...] dominar seu acontecimento aleatório" (FOUCAULT, 2011, p. 8-9).

Nesse sentido, compreendendo essa problemática estrutural, algumas são as formas de resistência que insurgem. Sobretudo no contexto do final da década de 1970 e década de 1980, diversos são os acontecimentos que motivaram a criação de espaços autônomos de reflexão e circulação de informação. Alguns que caberia citar são a reverberação das lutas pelos Civil Rights e dos movimentos de contracultura, nos Estados Unidos, nos anos 1960-1970, a ascensão de diversos movimentos sociais, a pressão social contra os regimes ditatoriais por toda América Latina e o próprio Maio de 1968 na França bem como a consolidação do

1 Essa discussão fica particularmente evidente em 2015 quando propõe-se nacionalmente a regulamentação econômica das mídias como forma de democratizar as informações e combater o monopólio de determinados grupos. Além disso, no presente, com a ampla circulação das fake news parece ainda mais urgente que a mídia assuma (ou reconquiste) sua função de fonte segura de informações. 
movimento Feminista, que viria a ser reconhecido como de 2a onda ${ }^{2}$ e que, nesse momento, passa a preocupar também pesquisadoras e a comunidade acadêmica em geral ${ }^{3}$ com questões sobre casamento, vida doméstica, maternidade, controle de natalidade, aborto, desejo e prazer da mulher.

No Brasil, embora ainda sob gestão militar, a reverberação dessas movimentações associada ao esgotamento do regime possibilitam a organização de diversos espaços de resistência política, sobretudo para além da ação política direta dos sindicatos e partidos, veículos de comunicação alternativos se multiplicam. No contexto de pesquisa atual, jornais alternativos produzidos por esses coletivos tornamse fontes de extrema importância para realização do exercício historiográfico de preencher ausências referentes a determinados grupos identitários, uma vez que tais

2 Há, sem dúvida, uma problemática em considerar o movimento feminista a partir de ondas, visto que dão a impressão de que a ação política de mulheres indivual ou coletivamente ocorre apenas de formas sazonais e a partir de pautas específicas, como por exemplo, a ideia de que a primeira onda feminista, no século XIX, tinha como pauta única a questão do direito ao voto. No entanto, essa foi uma pauta, sobretudo, na Europa e na América do Norte.Mulheres de países como Arábia Saudita receberam esse direito apenas em 2015, isto é, o voto não foi uma luta contínua e não pontual. Além disso, a ideia de unidade vem historicamente ocultando outras movimentações de mulheres e mesmo outras questões extremamente importantes, sobretudo, de mulheres do sul global. Nesse sentido, aqui utilizara-se a ideia de segunda onda feminista apenas para marcar sua simultanedade ao período da ditadura civil militar brasileira. No entanto, diversas das pautas da época ainda seguem em discussão sem qualquer indício de solução, como é o caso do direito ao abordo seguro e gratuito.

3 Será nesse momento que, por exemplo, os departamentos, os grupos de pesquisa e os eventos sobre "Mulher e literatura" serão criados nas universidades. Tais espaços tornam-se potentes centros de pesquisa e reflexão sobre feminismo e estudos de gênero, que na década seguinte, precisamente 1984, culminam na criação do GT Mulher e literatura (posteriormente, "A mulher na literatura") da ANPOLL. 
publicações se propuseram a buscar ocupar espaços contrahegemônicos por meio de estratégias de circulação de informação tanto de conotação mais política, de ação direta, quanto mais artísticas e culturais.

Nesse sentido, observando diretamente o papel e a função de jornais feitos por e sobre mulheres, cabe compreender o contexto da vasta produção e circulação de jornais que tratam especificamente dessa questão. Nesse sentido, três chamam principalmente atenção: O Brasil Mulher (1975), do Paraná, Nós mulheres (1976) e o Mulherio (1981), esses dois de São Paulo. Os dois primeiros voltados à questão de classe e esse último mais preocupado com questões de gênero. É isso o que afirma Elizabeth Cardoso (2004), organizando os mais de 75 periódicos feministas que circularam pelo Brasil entre os anos 1970 e 1980:

Em linhas gerais, porém, foi possível traçar características das publicações da primeira geração e características das publicações da segunda geração. Nota-se que, enquanto a primeira está marcada pelo debate entre "questão da mulher" versus "questão geral", feminismo liberal versus feminismo marxista ortodoxo, por reivindicações de ações públicas que coloquem as mulheres em igualdade com homens, pela questão da autonomia partidária e pelo combate a ditadura, já a segunda geração da imprensa feminista incorpora o conceito 
de gênero, assume os temas relacionados direta e exclusivamente às mulheres (como sexualidade, planejamento familiar e violência contra a mulher); tende para a especialização por temas; luta pelo direito à diferença e opera em parceria com um novo ator social, a sociedade civil organizada, na forma de ONGs e associações voltadas para a questão de gênero. (CARDOSO, 2004, p. 36)

Essa análise é particularmente importante, uma vez que insere o Mulherio, jornal que será analisado aqui, em um lugar específico de preocupações teóricas e contextuais, isto é, nessa segunda geração referida pela autora. Nesse sentido, mesmo que os jornais de mulheres tenham sido excluídos e apagados por outros estudos de importante circulação ${ }^{4}$, a pesquisa realizada pela autora apresenta ainda conclusões de extrema relevância sobre a imprensa feminista no Brasil:

i) a imprensa feminista é um fenômeno nacional, tendo em vista que a pesquisa constatou publicações feministas em todas as regiões do país, salvo a região Norte; ii) a imprensa feminista é um fenômeno contínuo e vigoroso socialmente, já que suas publicações são editadas ininterruptamente, desde 1974 até nossos dias; e iii) a imprensa feminista pode ser dividida em duas gerações, em simetria com as opções do movimento feminista. (CARDOSO, 2004, p. 51)

4 A pesquisadora aponta especificamente a pesquisa de Nelson Werneck Sodré (História da imprensa no Brasil, 1999) e de Bernardo Kucinski, sobre a imprensa alternativa no Brasil (Jornalistas e revolucionários, 1991). 
As definições de Elizabeth Cardoso alertam para a necessidade cada vez mais evidente de revisão acerca dos apagamentos históricos das mulheres, isto é, de recuperações historiográficas como a que se propõe aqui. Nesse sentido, os jornais de mulheres/feministas se tornam importantes fontes de pesquisa, pois constituem a história do Brasil e, portanto, devem ser encarados como fenômenos de comunicação, uma vez que circulam conceitos como "mulher", "gênero" e "feminismo", além de outros temas e discussões sociais pela perspectiva de mulheres, como a produção artística, literária e cultural de mulheres.

Apesar da fundamental importância das constatações, sobretudo, quantitativas de Cardoso (2004), há uma necessidade também mais qualitativa focada em cada um desses periódicos. Assim, restringindo a análise aos três principais jornais já citados, Constância Lima Duarte (2019) alerta que eles serviram como uma espécie de porta-voz feminino pela Anistia e também abertamente feminista, pois apresentam temas como o aborto, a mortalidade materna, as relações entre mulheres e política, o trabalho feminino, a dupla jornada, a prostituição, questões raciais, tendo ainda algumas contribuições sobre literatura, teatro e cinema.

Nesse sentido, interessa especificamente o periódico Mulherio, uma vez que o momento de sua criação e circulação 
marcam um momento importante da história do Brasil e do feminismo no Brasil, pois passa a haver uma ampla divulgação do tema de forma marcadamente política, isto é, feminista, e filiada, em certo sentido, a história do feminismo, visto que o próprio nome do jornal, assim como a palavra Suffragettes ${ }^{5}$, partem de estereótipos machistas e infantilizadores sobre as mulheres, mas que são ressignificados pelos movimentos de mulheres. Sobre isso, Adélia Borges comenta na edição de abertura do jornal: "Sim, nós vamos nos assumir como o Mulherio e, em conjunto, pretendemos recuperar a dignidade, a beleza e a força que significam as mulheres reunidas para expor e debater seus problemas" (BORGES, 1981, p. 1).

Assim, focalizando nesse jornal, interessa aqui, com objetivos historiográficos de reencontrar escritoras apagadas pelo discurso hegemônico, não apenas observar os temas específicos à condição da mulher e ao feminismo das décadas de 1970-1980, mas perceber, especificamente, a intersecção entre essas questões e a produção e crítica literária por e sobre escritoras mulheres.

\section{MULHERIO: UM PANORAMA}

O Mulherio, criado por iniciativa de feministas ligadas à Fundação Carlos Chagas, ganha enorme prestígio no 
meio universitário, tendo em seu terceiro número mais de 3 mil assinaturas. Desde a primeira edição do jornal é possível perceber que o próprio conselho editorial do jornal preocupa-se diretamente com a questão feminista da representação da mulher visto que, na edição inaugural do jornal, a editora Adélia Borges ataca frontalmente a problemática que envolve a descoberta da imprensa brasileira do assunto "mulher", o que se evidencia em "as informações da imprensa sobre mulher ainda são, em geral, superficiais, esparsas e contraditórias. Falta justamente um veículo que se dedique de forma sistemática, aprofundada e abrangente a todos os problemas que afetam a mulher brasileira" (BORGES, 1981, p. 1), ou seja, há como motivação fundante uma preocupação com a representação da mulher tanto na mídia brasileira quanto nas artes.

Assim, fica evidente que o jornal tem um caráter de menor atuação política-prática, sendo, portanto, mais voltado ao universo acadêmico e cultural, apesar de que, ainda assim, muito tenha se falado sobre o processo de construção da Constituinte e outros direitos das mulheres. Nesse sentido, quanto aos temas abordados pelo jornal, Constância Lima Duarte afirma que

[e]m variadas seções havia desde denúncias de violência, da discriminação contra a 
mulher negra, aos temas da política do corpo, amamentação, trabalho feminino e da vida das operárias e da periferia das grandes cidades, além de matérias sobre a produção cultural de escritoras e os endereços de grupos feministas em todo o país. Alguns números tornam-se verdadeiros documentos da trajetória de mulher na construção de uma consciência feminista, tal a seriedade do trabalho realizado para a conscientização da cidadania e o avanço das conquistas sociais da mulher brasileira. (DUARTE, 2019, p. 43)

Nota-se, assim, que o Mulherio, como umjornal de importante circulação, estrutura-se de uma forma a se preocupar não apenas com questões sociais e da vida política, mas também com espaços de reflexão sobre as mulheres, como os grupos de pesquisa que começam a existir pelas universidades de todo o Brasil e as manifestações culturais e artísticas de ou sobre mulheres. Assim, por exemplo, reportagens sobre a literatura escrita por mulheres ou ainda sobre o teatro e o cinema, dando destaque justamente para a questão da autoria, apresentam-se nas edições com certa frequência.

Em sintonia Viviane Gonçalves de Freitas (2017) analisa em sua tese quatro jornais feministas publicados entre 1970 e 2010, dentre os quais o Mulherio. Para a pesquisadora, o jornal dividiu-se em três fases: a primeira de abril/maio de 1981 a setembro/outubro de 1983, em cujos objetivos 
estavam o intercâmbio entre as diversas instituições e pesquisadoras voltadas ao estudo da condição da mulher. O conselho editorial dessa fase contava com 16 mulheres, dentre elas a antropóloga Ruth Cardoso e a psiquiatra Maria Rita Kehl. É importante destacar ainda que "a mobilização dos movimentos que reivindicavam punição judicial para os maridos e companheiros que agrediam e assassinavam as mulheres - que ganhou destaque em várias edições do Mulherio - foi muito importante para essa mudança de entendimento social" (FREITAS, 2017, p. 97).

Já a segunda fase de maio/junho de 1984 a abril/maio de 1988, após perder apoio financeiro institucional em 1983, em que o jornal fica 7 meses sem circular, ele volta em 1984 em edições bimestrais com o objetivo de ser "um contraponto aos outros órgãos de imprensa, que, em geral, tratam a mulher de um modo esquizofrênico" (BORGES, 1984, p. 2). É importante notar nessa fase uma preocupação não apenas com a necessidade de circulação das discussões feministas, mas com a própria representação das mulheres pelas mídias, o que pode ser estendido também a uma maior preocupação no âmbito das representações artísticas. Além disso, o Núcleo de Comunicação do Mulherio "apresentava uma nova proposta: sempre que possível, haveria o contraponto do 
homem às experiências femininas. Essa nova linha editorial vincula-se à crise do feminismo" (FREITAS, 2017, p. 97).

Assim, ao longo de suas 42 edições (1981-1988), com uma lacuna de 7 meses, contando com importantes colunistas até hoje reconhecidas, como a já mencionada psiquiatra Maria Rita Kehl, a escritora e ensaísta Lúcia Castello Branco e a militante, filósofa, escritora e antropóloga Lélia Gonzalez, o jornal publicou

diversos formatos de textos, como artigos, cartas à redação, entrevistas, resenhas de livros, críticas de cinema e TV, charges e matérias. $O$ jornal também abordava outros temas relevantes para o debate social, principalmente para a agenda dos movimentos feministas, que perduram até os dias de hoje - como a legalização do aborto ou que recentemente conseguiram avanços legislativos importantes - um exemplo é a PEC das Domésticas. (FREITAS, 2017, p. 99)

Sobre essa produção, Viviane Gonçalves de Freitas (2017) realiza um levantamento quantitativo em relação à presença de determinados temas nas publicações. De acordo com a pesquisadora, os assuntos mais presentes foram: organizações de mulheres (16\%), família (13\%), direitos sexuais e reprodutivos (10\%), discriminação das mulheres (8\%), política institucional (7\%), mídia e produção cultural (6\%), trabalho (6\%), estudos sobre mulheres (5\%), violências 
contra mulheres (4\%) e comunidade negra (3\%). Ao todo, foram contabilizados 1.757 textos jornalísticos, somando o material das 42 edições.

Dessa forma, a partir da pesquisa de Freitas (2017), o tema mídia e produção cultural manifesta-se com certa recorrência durante todo o tempo de existência do jornal. Isso evidencia que, embora como tema menos relevante, a crítica literária assume um papel importante no jornal e, por consequência, para a formação de um cânone alternativo ao hegemônico, consolidado por jornalistas e pesquisadoras feministas. Devido a isso, objetiva-se aqui analisar a partir de agora tanto a presença e as reflexões dessas críticas literárias quanto resgatar escritoras apagadas pela crítica literária hegemônica.

\section{A CRÍTICA LITERÁRIA FEMINISTA E A QUESTÃO HISTORIOGRÁFICA}

O papel da crítica literária é geralmente caracterizado pela avaliação de um texto, tanto no que diz respeito à sua definição enquanto literário, quanto do julgamento de seu valor artístico. No entanto, a crítica literária em muitos sentidos se desenvolveu e se afastou dessas ideias tão divulgadas no século XIX. Como aponta o teórico francês Antoine Compagnon (2010), a própria ideia de crítica é questionada. Desde o momento da institucionalização 
da história da literatura como disciplina universitária, a crítica literária passou a ser vista como impressionista ou dogmática, já que se baseava em impressões individuais e pessoais, ou ainda morais. Nas palavras de Roberto Acízelo de Souza "o ponto culminante do processo: o julgamento dos méritos da obra, tendo como critérios combinados a sua capacidade de propor padrões de honra e virtude [...] e a conformidade a modelos de gêneros chancelados pela tradição [...]" (2014, p. 19).

O comentário traz consigo uma importante questão no que diz respeito à crítica literária: a questão da tradição, ou em outras palavras, a questão do cânone e da história da literatura. Embora o autor discuta a crítica do século XIX, contemporaneamente, se a função da crítica é selecionar, a função da história literária é, certamente, arquivar, o que faz com que uma não exista sem a outra e, não raro, sejam funções desempenhadas pela mesma pessoa. No entanto, há no campo literário (crítica, história e até mesmo teoria) uma tentativa de incorporação de conceitos linguísticos (formalistas e estruturalistas) que supõe uma espécie de objetividade e, consequente, neutralidade no lido com o texto literário. Sobre isso, porém, é importante lembrar que "não existem elementos linguísticos exclusivamente literários, a literariedade não pode distinguir um uso literário e um uso não literário da linguagem" (COMPAGNON, 2010, p. 41). 
Além disso, Heloisa Buarque de Hollanda (1994) alerta para o mito da linearidade da história da cultura ocidental e o mito da falsa objetividade do historiador como duas questões cruciais para pensar a historiografia literária feminista visto que essas duas ideias acabam criando a falsa noção de que a história literária hegemônica em verdade é a únidade possível, pois é a única "científica". Esse mesmo argumento, por sua vez, cria um campo de legitimação de saberes sobre a literatura. Assim, a escrita, crítica e, por consequência, história literária são funções e propõem ferramentas a partir de modelos que excluem as mulheres, isto é, que excluem a diferença, visto que a literatura do homem é eleita como modelo universal. Sendo, portanto, essa a premissa da consolidação de um cânone oficial quase exclusivamente masculino, que reverbera e reitera, a partir de uma crítica hegemônica, seus próprios valores.

No entanto, o empenho da crítica feminista tem sido a de resgatar escritoras historicamente apagadas, não necessariamente por sua suposta falta de qualidade literária, mas especificamente por sua função e seu papel de gênero, uma vez que sua ideias e proposições literárias acessavam áreas da subjetividade das mulheres com as quais a crítica tradicional não estava preparada para lidar. 
Tal percepção, o apagamento e a "inadequação" ao cânone, fica ainda mais evidente quando Hollanda (1994) indica que a partir de pesquisas sobre mulheres escritoras em primeiro lugar encontra-se uma vasta produção. Muitas são as mulheres redescobertas e muitas são as novas tendências literárias propostas por elas. Isso reforça que essas exclusões e silenciamentos não tratam apenas de algumas poucas mulheres, mas de várias, inúmeras, o que revela uma estratégia estrutural da crítica literária. Além disso, em segundo lugar, a pesquisadora reforça a tensão entre a produção de mulheres e a história oficial afirmando que "os objetos recuperados, na maior parte das vezes, não 'cabiam' nas lacunas da história oficial tal como esta foi e vem sendo desenhada" (HOLLANDA, 1994, p. 456).

Nesse sentido, tais movimentações feministas nos campos críticos, teóricos e históricos da literatura evidenciam cada vez mais tais problemáticas, sobretudo, a partir das décadas de 1970 e 1980. No entanto, esse trabalho de recuperação histórica e exercício crítico parece ainda estar longe de seu fim, pois o cenário contemporâneo ainda é de extrema desigualdade. Isso é o que se pode constatar, por exemplo, ao observar que na Academia Brasileira de Letras menos de $6 \%$ de seus homenageados são escritoras mulheres e 
um percentual ainda menor de escritoras negras. Ainda é possível observar as premiações e concursos literários índices similares.

Tais indicativos evidenciam não apenas a necessidade mas a urgência do exercício historiográfico feminista ${ }^{6}$, pois em consonância com Heloisa Buarque de Hollanda, a professora Rita Schmidt (2019) evidencia que "os textos de autoria de mulheres levantam interrogações acerca de premissas críticas e formações canônicas, bem como tensionam as representações dominantes calcadas no discurso assimilacionista de um sujeito nacional não marcado pela diferença" (SCHMIDT, 2019, p. 66). Isso significa assumir que a produção de mulheres, recuperada a partir do exercício historiográfico da crítica literária feminista, acaba por renovar paradigmas historicamente consolidados sobre sujeito, sujeito histórico, identidade, nação e, por consequência, literatura.

Assim, portanto, o exercício de recuperação do passado a partir da escrita de mulheres apresenta-se não apenas como importante à construção de uma história de mulheres, mas também à construção de uma história da literatura

6 Sempre relevante o comentário de que a desigualdade no cenário da literatura ainda é uma realidade no presente, o que se pode confirmar a partir da pesquisa de Regina Dalcastagné (2012), a qual evidencia que entre 1990 e 2004 e pelas editoras Companhia das Letras, Rocco e Record, apenas $1 / 4$ dos livros publicados têm mulheres como autoras e $93,9 \%$ são brancos (homens e mulheres). 
enquanto uma alternativa contra-hegemônica, plural e diversa. Sendo assim, será justamente trazendo à tona, fazendo com que a literatura de autoria de mulheres seja recuperada, divulgada e lida, que paradigmas e conceitos da tradição serão repensados.

Dessa forma, essa é a finalidade da pesquisa aqui desenvolvida, em que foram analisadas todas as edições do Mulherio para se encontrar as colunas em que a crítica literária se apresentava. Além das duas últimas edições, quando o Mulherio torna-se o Nexo - Feminismo, informação e cultura, as seções que se dedicam a abordar questões literárias intitulam-se Cantinho das Letras, Literatura, Leitura, Memória e Ficção e são compostas por resenhas de livros, opiniões, entrevistas, críticas sobre o trabalho das escritoras que são divulgadas ao longo das edições do jornal. Dentre as responsáveis por produzir tais colunas estão os nomes de Sandra Lapeiz, Elizabeth Souza Lobo, Ligia Averbuck, Eliane Maciel, Maria Otillia Bocchini, Maria Carneiro da Cunha, Walnice Galvão, Dinorath do Valle, Maria Lúcia de Barros Mott, Lúcia Castello Branco, Nádia Batella Gotlib e Silvia Cintra Franco.

No entanto, foram nas seções Literatura, Memória e Fiç̧ão em que as questões literárias foram abordadas com 
maior ênfase, priorizando a divulgação de obras e autoras desconhecidas por meio de entrevistas e análises críticas de suas obras, visto que nas outras apresentavam-se críticas a textos de escritores homens (Cantinho da Letras) ou apenas apareciam pequenas notas ou comentários sobre algum acontecimento no universo de circulação, publicação e premiação de escritoras mulheres. Assim, nas edições 13, 14, 16, 26, 29, 32 e 33 é possível encontrar entrevistas com respectivamente as escritoras Dacia Mariani, Cassandra Rios, Cora Coralina, Isabel Allende, Doris Lessing, Maria Elisabete Lima Mota e Adélia Prado. Para além do levantamento dessas escritoras, observou-se também a presença das autoras atualmente reconhecidas no cenário da literatura brasileira, tais como Clarice Lispector, Lya Luft, Lygia Fagundes Telles, Adélia Prado e Marina Colassanti ao longo das edições do jornal.

As resenhas e análises críticas a que se ocupam as colaboradoras nas seções de Leitura e Fiç̧ão contemplam obras recém lançadas no Brasil, desde as nacionais até as traduzidas e, na seção Memória, destaca-se principalmente o levantamento feito pela historiadora Maria Lúcia de Barros Mott (1987). Sem muitos detalhes críticos, na edição de no 32, a pesquisadora lista uma série de livros publicados por 
mulheres entre os anos de 1965 e o momento da publicação do jornal. São eles ${ }^{7}$ : Diário de uma garota, de Maria Julieta Drummond Andrade (Rio de Janeiro, 1985); Uma vida como outras, de Helena S. de Castro Azevedo (São Paulo, 1955); Por onde andou meu coração, de Maria Helena Cardoso (São Paulo, 1984); Aluna do telhado, de Clotilde do Carmo Dias (São Paulo, s.d.); Anarquistas, graças a Deus, de Zélia Gattai (Rio de Janeiro, 1979); Um chapéu para viagem, de Zélia Gattai (Rio de Janeiro, 1982); Os anos 40, de Rachel Jardim (Rio de Janeiro, 1987); Ela e a reclusão - O condenado poderia ser você, de Vera Tereza de Jesus (São Paulo, 1965); Minha vida de menina, de Helena Morley (Rio de Janeiro, 1969); Rua sem fim, de Conceição da Costa Neves (São Paulo, 1984); O exercício da paixão, de Giselda Laporta Nicolelis (São Paulo, 1985); Tudo em cor-de-rosa, de Yolanda Penteado (São Paulo, 1977); e Paisagem e memória, de Helena Silveira (São Paulo, 1983).

Ainda, na edição seguinte, no 33, Maria Lúcia de Barros Mott (1987) prossegue com o inventário de escritoras. Recupera mais três autoras e solicita aos(às) leitores e leitoras que enviem mais títulos. Os livros nomeados são $O$ monstro de Olhos Azuis, de Tonia Carrero (Porto Alegre, 1986), a

7 Algumas dessas escritoras, como Tonia Carrero, Eros Volúsia (filha da Gilka Machado), Maria Julieta Drummond Andrade (filha do Carlos Drummond de Andrade), Zélia Gattai (esposa do Jorge Amado), Rachel Jardim, Helena Morley e Giselda Laporta Nicolelis aparecem em pesquisas acadêmicas já com o intuito de investigação e recuperação de sua trajetória a partir da análise de suas produções literárias. 
narrativa em terceira pessoa, de acordo com Mott, tenta desvendar a identidade da autora através da perspectiva de uma personagem e "acaba enveredando sem pudor pelo emaranhado mundo das relações familiares" (MOTT, 1987, p. 21); Companheiros de viagem, de Deocélia Vianna (São Paulo, 1984); e Eu e a dança, de Eros Volúsia (Rio de Janeiro, 1988), que apresenta relatos de vida, a percepção da autora sobre a dança, entrevista com a sua mãe (Gilka Machado), "além de poemas e apresenta um belíssimo material iconográfico"(MOTT, 1987, p. 21).

Além da forte preocupação em proporcionar às leitoras do jornal o acesso à produção de mulheres escritoras de forma quantitativa, até mesmo como um exercício historiográfico, há também, em outras edições, o desenvolvimento dessa produção de forma qualitativa. A fim de aprofundar essa questão, em um primeiro momento, dentre algumas mais famosas como Clarice Lispector e Adélia Prado, ressaltamse as entrevistas com Cassandra Rios na edição de nํ 14, de julho de 1983 e com Maria Elisabete Lima Mota, a poeta da sarjeta, na edição no 32, de setembro de 1987. Em seguida, analisa-se a polêmica em torno do não reconhecimento de Dinorath do Valle, a qual não apenas figura como tema da edição no 19 com a publicação de um trecho de seu romance 
premiado e mesmo assim ignorado pela sua editora, mas também como resenhista e colaboradora do jornal.

Nesse sentido, o primeiro caso que merece atenção é a entrevista com Cassandra Rios $^{8}$ realizada por Eliane Robert Moraes e Sandra Lapeiz. A autora sinaliza pontos cruciais de sua vida e obra, como a censura, a escrita feminina e as dificuldades que as escritoras têm ao submeter seus originais às editoras. A autora comenta que devido à censura passou a criar pseudônimos para tentar mostrar que a escrita dela não era pornográfica: “Acabei criando uma literatura que vinha de uma revolta porque eu nunca aceitei toda aquela proibição, eu nunca aceitei porque eu nunca fui pornográfica, eu sou realista. Nunca fui detratora também. Nunca fui subversiva: eu sempre me considerei apolítica" (MORAES E LAPEIZ, 1983, p. 10). Assim, a autora cria pseudônimos do sexo masculino, o que, em certa medida, caracteriza a busca pela aceitação de sua literatura sem depreciações quanto à temática. Em contraponto a isso, ao ser questionada sobre a linguagem supostamente própria à mulher, a escritora responde que

8 O erotismo em Cassandra Rios foi alvo de censura e proibição na época em que lançou suas obras. Foi considerada a artista mais perseguida durante a ditadura e seus textos não falavam de política. Mesmo em meio a tantas tentativas de silenciamento e apagamento de sua obra, a autora conseguiu viver uma vida confortável com as vendas de seus exemplares. Atualmente, observa-se que suas obras voltam a dialogar com determinados públicos e, ainda, constatou-se que desde 2006 Cassandra Rios vem sendo alvo da produção de teses e dissertações nos cursos de pós-graduação de História e de Literatura, com fomento dos órgãos federais. 
[n]ão existe isso de escrever como um homem, ou de escrever como uma mulher, porque o espírito, o estilo é tão próprio que você jamais poderá descobrir se um livro sem capa foi escrito por um homem ou por uma mulher. O escritor não tem sexo, não adianta querer decifrar. É a força do estilo. Então por que o estilo é tão forte, de envergadura, e de fôlego é corajoso dizer por isso que foi escrito por um homem, não, não é isto, porque tem muita mulher aí que é tida como homossexual porque ela escreve forte e com brilho, e não se admite que seja a força de uma mulher. (MORAES E LAPEIZ, 1983, p. 10)

Dito isso, a autora ainda relembra a experiência de uma outra escritora que teve de criar pseudônimos masculinos para publicar, pois como mulher era rejeitada. Percebe-se dessa forma que, mesmo afirmando que a escrita/escritor não tem sexo, Cassandra Rios cria pseudônimos masculinos para que ela mesma possa fazer parte de um circuito literário sem sofrer censura.

Tão consciente quanto Cassandra Rios da censura, Maria Elisabete Lima Mota ${ }^{9}$, uma escritora e poeta em situação social completamente diferente de Rios, também concede ao Mulherio uma entrevista. A entrevista convida a conhecer o universo por onde transita a autora e, por consequência, suas personagens e seus temas. A poeta da sarjeta, como

9 Até o momento nenhuma pesquisa sobre a autora foi encontrada. 
se apresenta, é uma filha de militar, moradora da favela do Carandiru, mãe de três filhas, casada e abandonada, tendo passado por períodos de alcoolismo e uso de drogas, além de ter sofrido com estupros e ter sido coagida à prostituição.

Para além da biografia da poeta, no momento da entrevista já havia publicado três livros de poesia, sendo o primeiro, Poesia da Sarjeta, mimeografado com a ajuda de Mara do Amaral, voluntária da OAF - Organização do Auxílio Fraterno. Já o segundo e o terceiro são lançados por editoras: Ave Vagueira (Editora Paulinas) e Declaro que estou em tormento (Editora Espaço e Tempo, com distribuição da Vozes). No entanto, a escritora, que também já foi obrigada a pedir esmola na rua, afirma a dificuldade que é viver de literatura: "viver com essa renda foi impossível. Tudo o que consegui foi uma série de entrevistas para a televisão, uma dentadura nova, passeios com as minhas filhas, além de algumas internações em manicômios" (MAGESTE, 1987, p. 11).

A simplicidade, o realismo e a objetividade na fala da poeta chamam atenção principalmente porque no momento em que vive, ditadura civil-militar, a sua existência já figura como uma forma de subversão. Não bastasse isso, no momento da entrevista, a autora se preparava para a publicação de um novo livro, A filha do militar, em que 
conta a sua própria história mesclada com a de seu pai, que esteve entre o grupo de soldados que combateu Lampião. Sobre a publicação no contexto da época comenta: "O meu pai foi usado. Foi um barato escrever esse livro, a história é muito bonita. Vou publicar nem que os militares me cubram de porrada, nem que cortem a aposentadoria do meu pai. Ai eu escrevo "O desaposentado da polícia Militar" (MAGESTE, 1987, p. 11). Nesse caso, a poeta e prosadora evidencia seu posicionamento crítico em relação aos militares e a sua consciência sobre as censuras que pode sofrer pela sua escrita.

A vida e a obra da autora se misturam não apenas ao longo de sua entrevista, mas a produção de Maria Elisabete Lima Mota, no contexto de escrita de mulheres, ilumina uma existência geralmente mais apagada e invisibilizada do que a de outras mulheres: a da mulher pobre e a influência dessa situação em sua escrita. Sobre isso afirma "Esse negócio de hospital psiquiátrico vai acabar na minha vida. Não sou débil mental. Quando fico sem casa, piro, mas despiro sozinha quando encontro de novo a esperança de morar. Minha cura é moradia" (MAGESTE, 1987, p. 11). Embora não se comente especificamente as dificuldades de ser escritora em decorrência do seu gênero, essa questão pulsa em toda 
a entrevista: os abusos, os estupros, a prostituição forçada, a situação de mãe solo e reverberam em sua poesia: "Sou a prostituta / Sou o menor abandonado / Sou todas e todos / que todos deixaram de amar" (MAGESTE, 1987, p. 11). Por fim, cabe ressaltar que, muitas vezes, partindo desse poema muitas das entrevistas que ela deu acabaram orbitando sobre a sua prostituição. Algo que a incomodava muito, embora falasse abertamente de sua vida, o caso se refere a "no começo cheguei a me prostituir com um revólver apontado pra mim. Fui forçada" (MAGESTE, 1987, p. 11), isto é, uma coerção ao ato, um estupro. Ao que ela rebate, elencando uma série de outras funções e características suas, como "mulher direita", religiosa, mãe, casada, dona de casa etc. No entanto, carece ressaltar que o motivo de sua fama, a literatura, acaba ocupando um papel secundário em suas entrevistas para dar lugar a essa espécie de fetiche da crítica. Lembrando novamente o quanto as mulheres não podem fazer parte do campo literário.

Já, por fim, no caso da escritora Dinorath do Valle ${ }^{10}$, o que chama atenção não é uma entrevista, mas a polêmica

10 Dinorath do Valle foi relembrada por sua atuação como professora, escritora e jornalista em um recente trabalho de conclusão de curso de jornalismo da União das Faculdades dos Grandes Lagos de São José do Rio Preto. Na ocasião, as pessoas entrevistadas relembram a trajetória da autora e pontuam a importância de sua literatura para a perpetuação da história da cidade de São José do Rio Preto, em São Paulo. Além disso, uma escola estadual situada na periferia do município bem como a Casa de Cultura de São José do Rio Preto levam o nome da autora, conferindo prestígio e reconhecimento à sua história. 
em torno de sua premiação e o descaso editorial bem como as reverberações desse acontecimento. Isso porque a professora, escritora e jornalista foi vencedora do prêmio Casa das Américas, em Cuba, com o romance Pau Brasil, em 1982, e até 1984 a obra não havia sido editada pela Hucitec, editora responsável pelas obras da autora. Assim, na edição no 17, a provocação à editora Hucitec vem por parte da colaboradora Maria Otillia Bocchini que emite uma nota direcionada à editora e indaga: "Fosse um homem o vencedor brasileiro do Casa das Américas, será que essa editora (Hucitec) que está com os originais não teria já editado o livro, com todo o estardalhaço que ele merece?" (BOCCHINI, 1984, p. 19). Além disso, Bocchini comenta ainda que a obra da autora foi vencedora de diversos outros prêmios, dentre eles o Governador do Estado de São Paulo, em 1971, que levou cinco anos para receber a publicação do livro $O$ vestido amarelo, de 1976.

Após essa notícia, na edição de no 19, é disponibilizado para as leitoras uma página do romance Pau Brasil. Na prévia, acompanha-se a narrativa a partir das lembranças de uma filha que foi abusada pelo pai:

Mas por que o Pai põe a mão na gente? É louquejo também, com filha não se faz, amor de pai não é em peitos, pêlos. Ele agrada e desce, rebaixa, afunda, arria. Avança e a 
gente cala, demuda, dá um desespero! O regaçar da calcinha, o dedo explorando, demasias e descaramentos, destemperos que dão vergonha de contar até pra gente mesma, despreciada, desfeita, negligente, nem querendo saber das irmãs. Mas era tudo a mesma coisa, nos descuidos de casa pequena nada fica amoitado e dessabido. (VALLE, 1984, p. 7)

Com essa passagem, constata-se que a temática da violência doméstica, alvo de muitas reportagens do jornal e das reivindicações sociais, também está presente nas narrativas das mulheres, contribuindo para um registro íntimo do cotidiano das mulheres diante da sociedade patriarcal. No entanto, na mesma linha da indignação de Bocchini é possível se especular que a escritora sofre com a não reedição de seu livro, mesmo premiado, não apenas devido a sua condição de mulher, mas de uma mulher escritora que expõe as relações no seio da sociedade patriarcal tratando literariamente de temas como o abuso sexual. Nesse sentido, Dinorath do Valle, ao narrar aquilo que a sociedade não quer ver, acaba tensionando o próprio conceito de literatura e abre margem para que se pense uma espécie de "escrita feminina"11.

11 Em relação à sua escrita, foi publicado um artigo recentemente que apresenta dois contos da autora e as contribuições desses textos para retratar a condição da mulher na sociedade brasileira. $\mathrm{O}$ trabalho intitula-se "Dinorath do Valle: das personagens femininas a temas universais". 
Nesse sentido, ao relacionar tais questões da "escrita feminina" com a crítica literária feminista, destaca-se a reflexão trazida pela professora Lúcia Castello Branco na coluna intitulada Fiç̧ão, da edição no 25:

Afinal, as questões femininas atraíam sobretudo os homens, enquanto as mulheres continuavam em silêncio, desempenhando papéis que a ficção masculina thes reservava. E do próprio desconhecimento acerca de sua história, da carência de uma tradição literária, constrói-se o texto da mulher: essencialmente voltado para o eu, para a análise da emoção, para o privilégio do sensível, ou - o que é pior - visivelmente marcado pelo ressentimento, pelo tom de mágoa ou de agressão à crítica dos homens. Transformar a relação mulher e ficção, seja no que se refere à ficção escrita pelas mulheres ou acerca das mulheres, significa, antes de tudo, transformar radicalmente as relações entre a mulher e seu real. (BRANCO, 1986, p. 4)

Novamente a tensão sobre "escrita feminina" surge para desestabilizar a tradição literária. Isso porque, a partir do que pondera Branco, a subjetividade presente na escrita feminina dialoga com as suas condições de escrita. Do mesmo modo, pontua-se a necessidade de que uma relação entre a mulher e o seu real seja estabelecida a partir de sua escrita ficcional, que parte da sua intimidade e de suas memórias, isto é, de sua experiência enquanto mulher. 
Tais relações seguem sendo pontuadas por Lúcia Castello Branco em sua matéria intitulada "O insano percurso do ser" na coluna Leitura, da edição de no 28. Em seu texto, Branco recupera o livro Hospício é Deus, publicado em 1985, escrito por Maura Lopes Cançado, ficcionista mineira e colaboradora do jornal Brasil, analisa os elementos que compõem a obra e caracteriza a escrita da autora:

Hospício é Deus é diário de uma ficcionistapsicopata-mulher. Talvez por isso a realidade muitas vezes se evada e se deixe invadir pelo Real. Ou talvez por isso o Real algumas vezes escape, deixando-se tragar pela mais prosaica das realidades. Nesse jogo do texto feminino contracenam a memória e a invenção, o fato e o escrito, a vida e a ficção. "Não tem importância", nos diz a autora. Nesse jogo o que interessa não é exatamente o escrito, mas a escrita. Não propriamente a fugidia substância dos fatos, mas o tecido, a sinuosa tessitura da linguagem. Aí o sujeito se constitui. E se desconstitui. Aí o corpo feminino se encena. Aí, nessa sarabanda alucinada, reluz exuberante, o Real. A esta cintilância alguns chamam ficção, outro psicose. Aqui, no texto de Maura, neste lugar de desordem e da desmedida, atrevo-me a chamá-la simplesmente escrita feminina. (BRANCO, 1987, p. 6)

É interessante notar sobre isso que mais uma vez a autoria feminina está calcada em sua experiência vivida. Nesse trecho, inclusive, mais especificamente, em sua experiência 
corporal e sua memória em uma espécie de entrecruzamento com a possibilidade da ficcionalização. Lúcia Castello Branco ensaia por uma perspectiva psicanalítica e subjetiva algumas respostas para a tentativa de interpretação da obra literária produzida por mulheres, isto é, a escrita, e não o escrito, propriamente feminino.

No entanto, parece que mesmo a partir do exercício da pesquisadora de fundar uma crítica literária que se preocupe com o texto de mulheres em sua peculiaridade, a crítica literária especializada ou mesmo o público em geral, parece não ser tão receptivo aos novos paradigmas que tais percepções podem trazer à literatura. Em relação a isso, a matéria de Ligia Averbuck intitulada "O texto da initimidade", na edição no 14, discute o teor dos textos escritos por mulheres, bem como o tabu que permeia a publicação. Averbuck caracteriza brevemente a escrita feminina ao dizer que

[v]oltada para a esfera íntima - a única concedida - a literatura da mulher se fez confessional, pessoal, subjetiva. Nos textos destes diários, memórias, autobiografias é que se fez este registro íntimo, a história narrada do ponto de vista da subjetividade, a forma de expressão possível. No caso da história da mulher e sua incursão no mundo das letras esta é uma marca de identidade. (AVERBUCK, 1983, p. 11) 
Essas afirmações reforçam o exercício íntimo da externalização do eu, mesmo que ficcional, na escrita de mulheres, o que revela o caráter identitário e pessoal de tais escritas. No entanto, a escrita da mulher se torna um motivo de depreciação crítica como relata, na edição no 25, Silvia Cintra Franco, a experiência na 3ạ Bienal Nestlé de Literatura Brasileira sobre o tema "A mulher na literatura brasileira", visto que, como apontou a jornalista, as escritoras foram negativamente consideradas intimistas, subjetivas e pessoalistas, critério que, certamente, ainda segundo a jornalista, não mostram-se como negativos nas obras de escritores homens como Proust, Kafka, Dostoievski e outros (FRANCO, 1986, p. 6). Isso significa dizer que as características próprias da literatura escrita por mulheres, para uma crítica literária hegemônica, será justamente o motivo de sua depreciação, ou seja, a literatura de mulheres não é literatura, uma vez que é escrita por e sobre mulheres a partir de suas próprias subjetividades e não de subjetividades masculinas como é mais comum à crítica literária.

Tal pensamento corrobora a necessidade de uma recuperação histórica das mulheres apagadas, silenciadas e esquecidas com o objetivo de eleger critérios críticos próprios de interpretação de suas obras, uma vez que os 
critérios utilizados até o momento são os eleitos por uma tradição crítica masculina. Nisso, entre erros e acertos, a crítica literária feminista do Mulherio debruça-se sobre conceitos como o que "escrita feminina", a fim de oferecer ferramentas críticas para a análise de obras de autoria de mulheres a partir delas próprias. Além disso, evidenciase a necessidade de análise da crítica literária feminista sobre autoras em recuperação como Cassandra Rios, Maria Elisabete Lima Mota e Dinorath do Valle que têm suas obras, de importante circulação e reconhecimento ao seu tempo, apagadas, desconsideradas ou invisibilizadas pelas ideologias dominantes que negam os tensionamentos propostos à literatura pela escrita de mulheres.

\section{CONSIDERAÇÕES FINAIS}

Quarenta anos após a publicação da primeira edição do Mulherio a crítica literária feminista mostra-se incansável no seu exercício de recuperação do passado tanto com a finalidade de reencontro com escritoras silenciadas, invisibilizadas e apagadas quanto com a finalidade de colocar em foco as lacunas deixadas pelos historiadores na história da literatura brasileira e, por consequência, instrumentalizar a teoria literária reelaborando ou propondo novos conceitos que assumam a diferença como 
elemento fundamente e não apenas busquem assimilar algumas mulheres ao cânone masculino.

Nesse sentido, filiando-se à tradição de crítica literária feminista e considerando o contexto de produção e circulação desse e de muitos outros periódicos feministas também apagados por pesquisas sobre o tema, essa pesquisa buscou analisar as 42 edições em circulação entre os anos de 1981 e 1988 do jornal Mulherio (posterior Nexo - Feminismo, informação e cultura) focalizando o tratamento dado especificamente à questão da produção literária de mulheres.

Embora muitas questões envolvendo essa temática sejam relevantes e importantes, intencionou-se principalmente perceber 1) o tratamento dado à questão da recuperação história, sobretudo, por Maria Lúcia de Barros Mott; 2) o tratamento dado à questão da "escrita feminina", sobretudo, por Lucia Castello Branco e, por fim, 3) o tratamento dado às escritoras de importante circulação no período, mas que acabam atualmente, em diferentes medidas, apagadas da história literária, como é o caso de Cassandra Rios, Maria Elisabete Lima Mota e Dinorath do Valle.

Sobre essas questões, alguns pontos puderam ser concluídos. Em primeiro lugar evidencia-se a preocupação 
não apenas da colunista Maria Lúcia de Barros Mott ao apresentar uma vasta listagem de publicações de autoria de mulheres, mas do próprio jornal ao criar a seção Memória. Isso significa dizer que a condição primordial feminista certamente marca a necessidade de recuperação do passado que sabe-se, sem dúvida, apagado a partir de valores masculinos de história, literatura e, certamente, cânone.

Em segundo lugar, considerando aspectos tanto de produção, recepção e circulação de literatura de autoria de mulheres quanto da própria subjetividade das escritas de mulheres, a "escrita feminina", a literatura de mulheres parece não poder ocupar um espaço na literatura justamente por sua própria substância, isto é, características próprias da escrita das mulheres que começam a ser percebidas como comuns a muitas escritoras. Tais características fundamentaram a sua crítica negativa, como, por exemplo a questão do intimismo ou ainda o tratamento dado a temas como violência contra as mulheres pela perspectiva das mulheres.

O segundo ponto está atrelado diretamente ao terceiro ponto: os apagamentos pontuais de importantes escritoras como Cassandra Rios, Maria Elisabete Lima Mota e Dinorath do Valle, sendo que, em comum todas têm de tratar do 
desejo erótico das mulheres, e da violência contra as mulheres, sobretudo, abuso sexual, isto é, temas e questões absolutamente proibidos dentro da esfera pública. Assim, não é aleatório que tenham ficado conhecidas Cassandra Rios e Maria Elisabete Lima Mota, respectivamente, como escritora maldita e poeta da sarjeta, tendo, a primeira, inclusive, publicado com pseudônimos masculinos, estratégia de inúmeras escritoras ao longo da história. Dessa mesma forma, a falta de reconhecimento cultural e financeiro afeta também Dinorath do Valle que não tem seu romance reeditado mesmo quando premiado ou precisa esperar cinco anos para que outro texto seja publicado, mesmo que também tenha sido resultado de premiação. Esses três exemplos evidenciam uma série de dificuldades editoriais e culturais que grande parte (para não dizer todas) das escritoras mulheres enfrentam.

Assim, ciente desses processos, o jornal Mulherio busca reconhecer e apresentar ao público suas obras, ou seja, tem como vontade, parece, que essas mulheres não caiam em esquecimento como as que antes delas caíram. No entanto, esse exercício, em certo sentido, parece não ter repercutido com o resultado esperado, e essas autoras acabaram permanecendo apagadas e esquecidas. 
Isso não significa dizer que jornais alternativos não tenham sido de extrema importância, sobretudo, os que focaram em questões identitárias, como os jornais de feministas, porque são hoje um espécie de ponte com o passado documentado, uma fonte de pesquisa abertamente feminista e preocupada com a memória literária das mulheres. É justamente a existência desse e de outros jornais similares que possibilitam o crescente, ainda que tímido, número de pesquisas, nos últimos dez anos, sobre escritoras como Cassandra Rios e Dinorath do Valle e possibilita ainda o encontro com verdadeiras preciosidades como Maria Elisabete Lima Mota, ainda completamente apagada.

\section{REFERÊNCIAS}

AVERBUCK, Ligia. O texto da intimidade. Mulherio, São Paulo, ano 3, n. 14, jul./ago., 1983. Disponível em: https://www.fcc.org.br/conteudosespeciais/ mulherio/capas2.html. Acesso em: 25 de maio de 2020.

BOCCHINI, Maria Otília. Sai dessa, Hucitec!. Mulherio, São Paulo, ano 4, n. 17, p. 19, jul./ago., 1984. Disponível em: https://www.fcc. org.br/conteudosespeciais/mulherio/capas2.html. Acesso em: 25 de maio de 2020.

BORGES, Adélia. Por que Mulherio?. Mulherio, São Paulo, n. 0, p. 1, mar./ abr., 1981. Disponível em: https://www.fcc.org.br/conteudosespeciais/ mulherio/capas2.html. Acesso em: 25 de maio de 2020.

BORGES, Adélia. Vamos que vamos. Mulherio, São Paulo, n. 16, p. 2, maio/ jun., 1984. Disponível em: https://www.fcc.org.br/conteudosespeciais/ mulherio/capas2.html. Acesso em: 25 de maio de 2020.

BRANCO, Lucia Castello. Em memória de Judith, irmã de Shakespeare. Mulherio, São Paulo, ano 6, n. 25, p. 4, mar./ago., 1986. Disponível em: 
https://www.fcc.org.br/conteudosespeciais/mulherio/capas2.html. Acesso em: 25 maio 2020.

BRANCO, Lucia Castello. O insano percurso do ser. Mulherio, São Paulo, ano 7, n. 28, p. 6, mar./abr., 1987. Disponível em: https://www. fcc.org.br/conteudosespeciais/mulherio/capas2.html. Acesso em: 25 de maio de 2020.

CARDOSO, Elizabeth. Imprensa feminista brasileira pós-1974. Revista Estudos Feministas, Florianópolis, n. 12, 2004.

COMPAGNON, Antoine. $O$ demônio da teoria: Literatura e senso comum. Tradução de Cleonice Paes Barreto Mourão e Consuelo Fontes Santiago. 2. ed. Belo Horizonte: Editora UFMG, 2010.

DALCASTAGNE, Regina. Literatura brasileira contemporânea: um território contestado, Rio de Janeiro: Editora UERJ, 2012.

DUARTE, Constância Lima. Feminismo: uma história a ser contada. In: HOLLANDA, Heloisa Buarque (Org.). Pensamento feminista: formação e conceito. Rio de Janeiro: Bazar do Tempo, p. 25-45, 2019.

FOUCAULT, Michel. A ordem do discurso: aula inaugural do College de France pronunciada em 2 de dezembro de 1970. Tradução de Laura Fraga de Almeida Sampaio. 21. ed. São Paulo: Edições Loyola Jesuítas, 2011. FRANCO, Silvia Cintra. Bom mocismo na Bienal. Mulherio, São Paulo, ano 6, n. 25, p. 6, mar./ago., 1986. Disponível em: https://www.fcc. org.br/conteudosespeciais/mulherio/capas2.html. Acesso em: 25 de maio de 2020.

FREITAS, Viviane Gonçalves. De qual feminismo estamos falando? Desconstruções e reconstruções das mulheres, via imprensa feminista brasileira, nas décadas de 1970a 2010. 2017. 197f. Tese (Doutorado em Ciência Política) - Programa de Pós-graduação em Ciência Política da Universidade de Brasília, 2017.

HOLLANDA, Heloisa Buarque de. A historiografia feminista: algumas questões de fundo. In: FUNCK, Susana Bornéo. Trocando ideias sobre a mulher na literatura. Pós-Graduação em Inglês, Universidade Federal de Santa Catarina, Florianópolis, 1994. 
KUCINSKI, Bernardo. Jornalistas e Revolucionários: nos tempos da imprensa alternativa. São Paulo: Scritta Editorial, 1991.

MAGESTE, Paula. Poeta da sarjeta e da sensatez. Mulherio, São Paulo, ano 7, n. 32, set., 1987. Disponível em: https://www.fcc.org. br/conteudosespeciais/mulherio/capas2.html. Acesso em: 25 de maio de 2020.

MORAES, Eliane Robert; LAPEIZ, Sandra. Cassandra Rios, popular e maldita. Mulherio, São Paulo, ano 3, n. 14, jul./ago., 1983. Disponível em: https://www.fcc.org.br/conteudosespeciais/mulherio/capas2.html. Acesso em: 25 de maio de 2020.

MOTT, Maria Lúcia de Barros. Memória feminina contada em livros. Mulherio, São Paulo, ano 7, n. 32, p. 14, set., 1987. Disponível em: https://www.fcc.org.br/conteudosespeciais/mulherio/capas2.html. Acesso em: 25 de maio de 2020.

MOTT, Maria Lúcia de Barros. Memória feminina contada em livros. Mulherio, São Paulo, ano 3, n. 33, p. 21, out., 1987. Disponível em: https://www.fcc.org.br/conteudosespeciais/mulherio/capas2.html. Acesso em: 25 maio 2020.

RAMOS, Pâmela Coca. Dinorath do Valle: das personagens femininas a temas universais. Macabéa - Revista Eletrônica do Netlli, Crato, v. 10, n. 1, p. 169-187, 2021.

SCHIMIDT, Rita Terezinha. Na literatura, mulheres que reescrevem a nação. In: HOLLANDA, Heloisa Buarque (Org.). Pensamento feminista: formação e conceito. Rio de Janeiro: Bazar do Tempo, p. 65-79, 2019. SODRÉ, Nelson Werneck. História da imprensa no Brasil. 4. ed. São Paulo: Martins Fontes, 1999.

SOUZA, Roberto Acízelo de. História da literatura: Trajetória, fundamentos, problemas. São Paulo: É Realizações, 2014.

VALLE, Dinorath do. Dora. Mulherio, São Paulo, ano 4, n. 19, nov./dez., 1988. Disponível em: https://www.fcc.org.br/conteudosespeciais/ mulherio/capas2.html. Acesso em: 25 de maio de 2020. 
Jaísa Girardi Morais

Mestranda (Pontifícia Universidade Católica do Rio Grande do Sul PUC-RS).

Participação na organização do grupo de estudos "Leituras plurais: mulheres e literatura brasileira contemporânea".

http://lattes.cnpq.br/4127251271165958

https://orcid.org/0000-0002-8823-3946

jaisa.gm@gmail.com

Virgínea Novack Santos da Rocha

Mestra (PUC-RS).

Doutoranda (PUC-RS).

Coordenadora do grupo de estudos: "Leituras plurais: mulheres e literatura brasileira contemporânea".

http://lattes.cnpq.br/6588015523042326

https://orcid.org/0000-0002-3089-3298

novack.virginea@gmail.com 